\title{
Distribution of trace elements in core marine sediments of coastal East Malaysia by instrumental neutron activation analysis
}

\begin{abstract}
A study was carried out on the distribution and enrichment of trace elements in the core marine sediments of East Malaysia from three stations at South China Sea and one station each at Sulu Sea and Sulawesi Sea. Five stations of sediment cores were recovered and the vertical concentration profiles of six elements namely $\mathrm{Br}, \mathrm{Cs}, \mathrm{Hf}, \mathrm{Rb}, \mathrm{Ta}$, and $\mathrm{V}$ were determined using the instrumental neutron activation analysis. The enrichment factor, geoaccumulation index and the modified degree of contamination were used to calculate the anthropogenic and pollution status of the elements in the samples. Except for Cs and Hf, which by the enrichment factor are categorized from minimum enrichment to moderate enrichment in all stations and for $\mathrm{V}$ and $\mathrm{Rb}$ in Sulu Sea and Sulawesi Sea, which are categorized minimum enrichment, other elements are found to be no enrichment at all stations. The geoaccumulation index of $\mathrm{Hf}$ in one station shows moderately polluted and for other elements are unpolluted. However, the modified degree values of all samples are less than 1 , suggesting very low contamination of elements found in all the stations.
\end{abstract}

Keyword: INAA; Trace elements; Enrichment factor; Geoaccumulation index; Modified degree of contamination; Core marine sediments; East Malaysia 